\title{
Obesity and Thyroid Function in Children Cross-sectional study
}

\section{Background}

Obesity in children has been increasing dramatically, with a significant increase in cardiovascular and metabolic diseases risk. The role of thyroid dysfunction has been extensively analyzed in obese adults, but to a limited extent in children. Serum TSH values are often elevated in obese children and may be associated with modifications in lipid and glucose metabolism. However, the clinical relevance of these associations remains unclear.

\section{Aims}

- To estimate the prevalence of hyperthyrotropinemia in obese children;

- To analyze the influence of BMI-SDS and TSH in other metabolic variables.

\section{Methods}

Retrospective study with data from the first evaluation of obese children in our clinic. Demographic, anthropometric and metabolic variables were studied. Descriptive analysis consisted of frequency distribution for qualitative variables and mean \pm standard deviation for continuous variables. For the association between BMI-SDS, thyroid function and other metabolic variables, multiple linear regression models were used. A p-value $\leq 0.05$ was considered for statistical significance.

\section{Results}

\begin{tabular}{|c|c|}
\hline & $n=348$ \\
\hline Age (years) & $11,73 \pm 3,11$ \\
\hline Sex (Masculine/Feminine) (n) & $175 / 173$ \\
\hline BMI SDS & $2,92 \pm 0,65$ \\
\hline $\mathrm{TSH}(\mu \mathrm{UI} / \mathrm{mL})$ & $2,55 \pm 1,15$ \\
\hline fT3 (pg/mL) & $4,13 \pm 0,56$ \\
\hline fT4 (ng/dL) & $1,13 \pm 0,36$ \\
\hline HOMA-IR & $3,67 \pm 2,82$ \\
\hline Total colesterol (mg/dL) & $160 \pm 26,5$ \\
\hline $\operatorname{LDL}(\mathrm{mg} / \mathrm{dL})$ & $99,4 \pm 24,7$ \\
\hline $\mathrm{HDL}(\mathrm{mg} / \mathrm{dL})$ & $46,8 \pm 10,1$ \\
\hline Triglicerides (mg/dL) & $96,2 \pm 49,0$ \\
\hline $8,9 \%$ & $\uparrow \mathrm{fT} 4: 11,4 \%$ \\
\hline ubertal $(6,2 \mu \mathrm{UI} / \mathrm{mL}): 1,6 \%$ & - Pre-pubertal (1,72 ng/dL): $8,7 \%$ \\
\hline rtal $(3,7 \mu \mathrm{UI} / \mathrm{mL}): 13,2 \%$ & - Pubertal (1,47 ng/dL): $13,0 \%$ \\
\hline $5,0 \%$ & $\uparrow$ HOMA IR (2,5): 69,3\% \\
\hline ubertal $(5,14 \mathrm{pg} / \mathrm{mL}): 7,9 \%$ & - Pre-pubertal: $56,5 \%$ \\
\hline rtal $(4,9 \mathrm{pg} / \mathrm{mL}): 3,3 \%$ & - Pubertal: $80,3 \%$ \\
\hline
\end{tabular}

$\begin{aligned} \text { 个 TSH } & \rightarrow \text { 个fT3 }(p=0,024) \\ & \rightarrow \text { 个HOMA IR }(p=0,003)\end{aligned}$

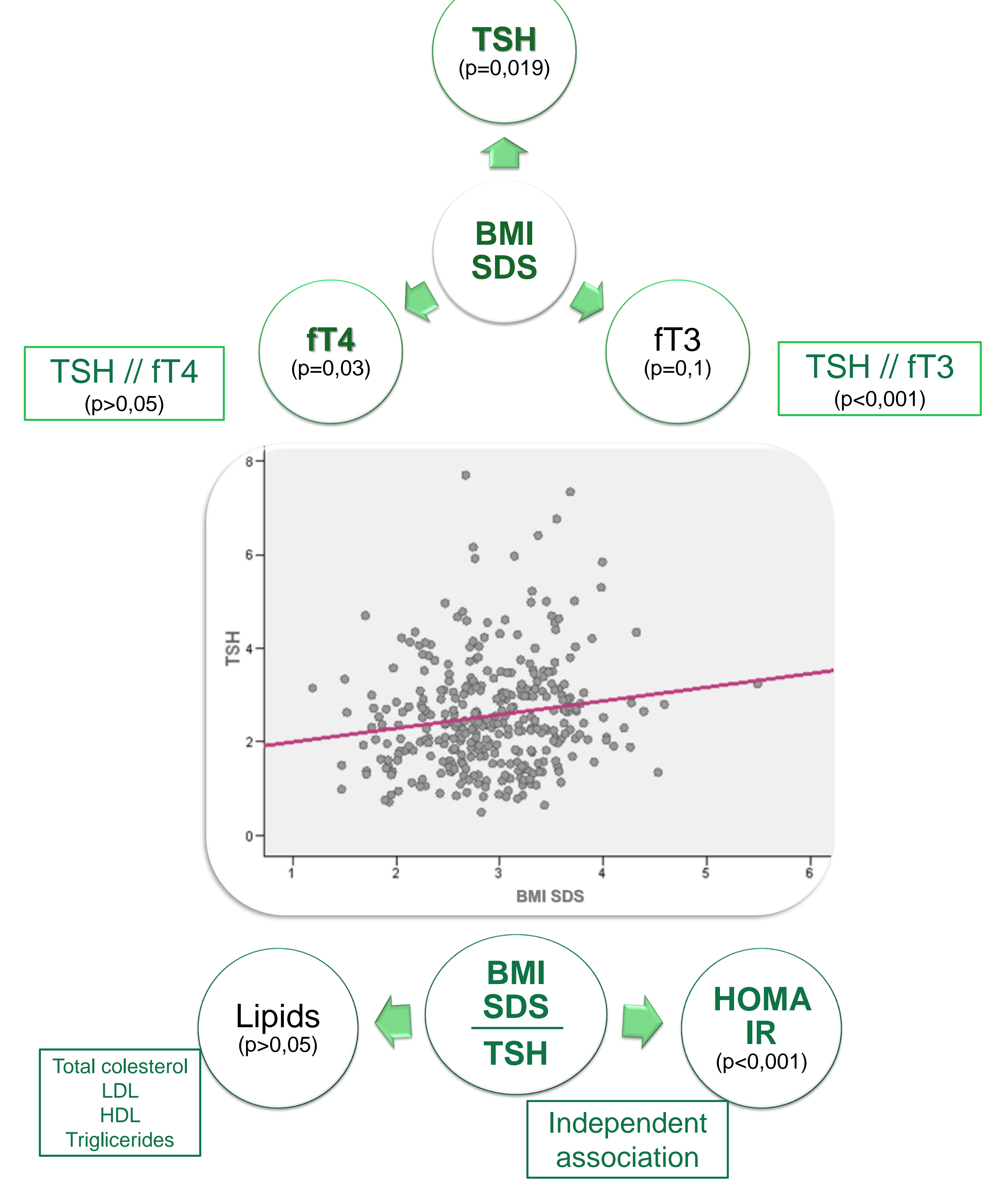

\section{Conclusions}

The prevalence of hyperthyrotropinemia was similar to that reported in other studies and appeared to be influenced by metabolic factors other than fT3 or TRH. Children with hyperthyrotropinemia had significantly higher fT3 and HOMA-IR. BMI-SDS was positively correlated with TSH, fT4 and HOMA-IR. TSH and BMI-SDS were positively and independently correlated with HOMA-IR, which suggests that hyperthyrotropinemia might exacerbate insulin resistance in obese children. 